\title{
Gestión de procesos incorporando la gestión del capital intelectual y la gestión del conocimiento: un estudio de aplicación a centros de investigación
}

\author{
Enrique Saravia Vergara \\ Candidato a Doctor en Sociedad de la Información y el Conocimiento por la \\ Universitat Oberta de Catalunya, España. \\ Master en Sociedad de la Información y el Conocimiento por la \\ Universitat Oberta de Catalunya, España. \\ Magíster en Administración por la Universidad del Pacífico, Lima, Perú. \\ Profesor e Investigador del Departamento Académico de Administración de la \\ Universidad del Pacífico, Lima, Perú.
}

\section{Resumen}

En el actual entorno competitivo, las organizaciones buscan crear valor para el cliente mediante enfoques de gestión que no solo garanticen la oferta de bienes y servicios de calidad y a bajos precios, sino que logren ventajas competitivas a largo plazo. En este contexto, la gestión de procesos asoma como un modelo de gestión basado en «calidad»; mientras que los modelos de gestión del «capital intelectual» y de «gestión del conocimiento» representan los principales modelos basados en la gestión de los activos intangibles, base del éxito competitivo del siglo XXI.

El presente estudio representa un ensayo que, a partir de un modelo de gestión de procesos aplicado a un centro de investigación y de la revisión del marco teórico correspondiente a las disciplinas del «capital intelectual» y la «gestión del conocimiento», analiza y propone un modelo de gestión de procesos en centros de investigación incorporando la Gestión del Capital Intelectual y la Gestión del Conocimiento.

Palabras clave: Gestión de procesos, capital intelectual, gestión del conocimiento, indicadores de gestión, centros de investigación.

\section{Introducción}

Las universidades en general, privadas y públicas, desempeñan un papel protagónico en la sociedad de la información y el conocimiento debido a la misión por las que fueron creadas: generar y transmitir conocimientos en la formación profesional de los estudiantes, y contribuir al conocimiento y al desarrollo de la sociedad en general. Las universidades son, o debieran ser, las «fuentes de conocimiento» en una sociedad, las entidades encargadas de generar nuevas teorías, metodologías o técnicas en las disciplinas en las que se desarrollan.

Sin embargo, la actual «sociedad de la información y el conocimiento» no solo determina nuevas características de las personas, organizaciones y sociedad en general, sino que también exige nuevos modelos de gestión de organizaciones, basa- 
dos en nuevas fuentes de competitividad empresarial. Como respuesta a los nuevos requerimientos del entorno empresarial, en el ámbito académico se han desarrollado modelos de «gestión de procesos» y de «gestión estratégica»y, aunque algunos modelos pretenden integrar estos dos aspectos (procesos y estrategia), estos se han enmarcado en dos «frentes» o perspectivas: el enfoque de procesos y el enfoque estratégico. El enfoque de procesos se basa en los clásicos modelos de gestión de calidad, que tienen sus orígenes en las técnicas de la «administración de la calidad total» o Total Quality Management (TQM); mientras que desde la perspectiva del enfoque estratégico, aparentemente, existe un consenso en que los activos intangibles tienen hoy un mayor potencial para generar ventajas competitivas. En este sentido, la "gestión del capital intelectual» y la «gestión del conocimiento» asoman como modelos alternativos de gestión.

En este contexto, se presenta este estudio de aplicación de la gestión de procesos en un centro de investigación universitario, incorporando la gestión del conocimiento y la gestión del capital intelectual.

\section{Objetivos del estudio}

El propósito central de este estudio es analizar la forma de integrar en un solo modelo la gestión de procesos, la gestión del capital intelectual y la gestión del conocimiento en un centro de investigación.

Para lograr la integración de estas tres disciplina, los objetivos específicos del estudio son:

- Identificar las variables clave y los procesos críticos en centros de investigación, bajo un enfoque de gestión de calidad.

- Identificar las variables clave y los procesos críticos en centros de investigación, bajo un enfoque de gestión del capital intelectual.

- Identificar las variables clave y los procesos críticos en centros de investigación, bajo un enfoque de gestión del conocimiento.
- Analizar y definir la forma de incorporar la gestión de capital intelectual y la gestión del conocimiento en la gestión de procesos de un centro de investigación.

\section{Marco conceptual}

De acuerdo con los objetivos del estudio, a continuación, se presentan los principales aspectos del marco teórico vinculado a cada una de las tres disciplinas involucradas:

\section{La gestión de procesos basado en la calidad}

El término gestión de procesos se está convirtiendo en un nombre genérico utilizado por varios modelos de gestión para referirse a los enfoques que priorizan la gestión, el análisis y el mejoramiento de los procesos de negocios.

Aunque existen varias definiciones en relación con el concepto, la mayoría coincide en definir proceso» al conjunto de actividades concatenadas entre sí que transforman elementos de entrada o input en elementos de salida o output. Mariño (2003: 9), por ejemplo, menciona varias definiciones para referirse al significado de un proceso, siendo una de ellas: "secuencia de acciones o conjunto de actividades encadenadas que transforman en productos o resultados con características definidas unos insumos o recursos variables, agregándoles valor con un sentido específico para el cliente».

Davenport (1996: 6) expresa que un proceso es un conjunto estructurado y medido de actividades, diseñado para producir un algo específico para un mercado o cliente determinado y que, por tanto, supone un énfasis especial en cómo se hace el trabajo dentro de la organización, contrastando con el énfasis especial en el enfoque de producto. Además, Davenport (1996: 7) agrega que enfocarse hacia el proceso implica adoptar el punto de vista del cliente, ya que los procesos son la estructura que permite producir valor para sus clientes. Por tanto, la "gestión de procesos» implica una gestión orientada al cliente, un enfoque de calidad concebida como satisfacción del cliente. 
Zaratiegui (1999) considera que «los procesos son posiblemente el elemento más importante y más extendido en las gestión de las empresas innovadoras, especialmente de las que basan su sistema de gestión en la Calidad Total», y que se han desarrollado dos tipos de técnicas de gestión de procesos. Por un lado, las técnicas para gestionar y mejorar los procesos, como, por ejemplo, el «método sistemático de mejora» y la «reingeniería», que constituyen una aplicación puntual a procesos concretos o de uso extendido a toda empresa; y, por otro lado, los modelos de gestión, como, por ejemplo, el «Modelo Europeo de Excelencia Empresarial-EFQM (por sus siglas en inglés)», el «mapa de procesos» y el «cuadro de mando integral», en donde los procesos desempeñan un papel central como base de la organización y como guía para articular el sistema de indicadores de gestión.

Mariño (2003: 1-7) considera que la gerencia de procesos tuvo su origen en el siglo XX, derivada de la disciplina de la calidad. Hasta inicios de ese siglo, los esfuerzos de gestión de calidad estaban basados en la inspección del producto terminado y en la mejora de la productividad mediante el enfoque de la administración científica propuesto por Federick Taylor. En 1924, el estadístico Walter Shewart propuso la técnica estadística «gráfica de control de procesos», reconociendo implícitamente que la calidad no solamente está presente en el producto terminado, sino que es resultado del proceso. Más adelante, diversos autores aportaron técnicas de mejoramiento de procesos, construyendo así lo que hoy se denomina «calidad total». Mariño también hace referencia a la familia de normas ISO como un sistema de calidad orientado a la gestión de procesos y, por otro lado, considera que existe un consenso respecto de que una organización exitosa moderna debe practicar la gestión de procesos basada en la filosofía de la calidad total, considerando así que la «gestión de procesos» constituye una versión moderna de la práctica de la calidad total.

La administración de la calidad total o TQM es una filosofía de gestión de procesos orientada a que una organización brinde bienes y/o servicios de calidad satisfactorios para el cliente y a precios razonables. Como propuesta metodológica, el TQM está basado en la aplicación del ciclo de mejora continua, ciclo de Deming o ciclo PDCA (Planning/Planear - Do/ Hacer - Check/Verificar - Action/Acción). Enfocarse en el proceso desde esta perspectiva implica identificar un problema de calidad mediante la identificación y el análisis de los atributos valorados por el cliente, la identificación o definición del proceso, y el análisis del proceso mediante el uso de las técnicas de control de calidad (Quality Management-QC).

Las normas ISO (International Organisation for Standardization) son un conjunto de reglas orientadas a asegurar la calidad y mejorar la productividad. Como sistema de gestión de calidad, ISO 9001 propone ocho principios para mejorar la calidad: Organización enfocada hacia el cliente; Liderazgo; Participación de las personas; Orientación hacia los procesos; Enfoque sistémico de gerencia; Mejoramiento continuo; Toma de decisiones basada en hechos; y Relación mutuamente beneficiosa con los proveedores. De estos ocho elementos, es importante resaltar que la orientación hacia los procesos y la toma de decisiones basada en hechos plantean decisiones basadas en la identificación de los atributos valorados por el cliente, la identificación de los procesos críticos y el análisis de datos e información mediante el uso de las herramientas que provienen de la calidad total. Adicionalmente, ISO pone énfasis en la identificación y el mapeo de procesos, así como en la «caracterización» 0 «documentación» de los procesos.

El Business Process Management (BPM) es un enfoque metodológico basado en modelar, analizar y gestionar los procesos del negocio y la arquitectura empresarial, permitiendo así asignar indicadores de gestión para su medición y monitoreo. El modelo enfatiza que el análisis de procesos debe basarse en elaborar un mapa de procesos (process mapping) que sirva de guía para el mejoramiento de estos últimos. 
Considerando estos aportes, a continuación se presenta una forma de aplicar la gestión de procesos en las organizaciones:

- Identificar los atributos valorados por el cliente 0 «elementos de valor» e identificar los «atributos críticos» mediante la evaluación de la satisfacción de clientes.

- Definir los procesos y representar la interacción entre ellos en un mapa de procesos.

- Identificar los «procesos críticos» a partir del análisis y la identificación de los procesos clave para mejorar los «atributos críticos».

- Documentar los procesos y definir indicadores de gestión de procesos.

- Analizar y mejorar los «procesos críticos» mediante el análisis de datos y el uso de las herramientas de control de calidad que provienen de la calidad total.

En el presente estudio se analiza la forma de aplicar los tres primeros puntos de esta metodología a los centros de investigación. Teniendo presente los objetivos del estudio, no se requiere las últimas dos fases relativas a la documentación y el análisis de los procesos críticos.

\section{La gestión del capital intelectual}

En el ámbito académico se han desarrollado varios modelos que tratan de explicar la creación de valor en las organizaciones, entre los que se pueden citar, a modo de ejemplos, la Gestión del capital intelectual (Intellectual Capital-IC); la Gestión del conocimiento (Knowledge Management-KM); la Administración de la relación con los clientes (Customer Relationship Management-CRM); la Gestión estratégica monitoreada con un cuadro de mando integral (Balanced Scorecard-BSC); la Administración de la cadena de suministros (Supply Chain Management-SCM); entre otros. Si analizamos estos enfoques de gestión estratégica, todos es- tán basados o están íntimamente ligados a la generación de valor en las organizaciones mediante la gestión de activos intangibles.

Hoy, existe un consenso sobre el gran potencial que tienen los activos intangibles para generar valor en las organizaciones. Lev (2003: 13) considera que

«la riqueza y el crecimiento en la economía de hoy en día vienen determinados principalmente por los activos intangibles (intelectuales). Los activos materiales y financieros se están convirtiendo en commodities, ofreciendo en el mejor de los casos una mediana rentabilidad. Beneficios anormales, posiciones competitivas dominantes y, en ocasiones, situaciones temporales de monopolio, son el resultado de la utilización juiciosa de intangibles, en conjunción con otros tipos de activos».

En este contexto, Kaplan y Norton (2000: 15) consideran que «la habilidad de una empresa para movilizar y explotar sus activos intangibles o invisibles, se ha convertido en algo mucho más decisivo que invertir y gestionar sus activos tangibles y físicos» ${ }^{1}$. Navas y Ortiz de Urbina (2002) consideran que

«los activos intangibles se están convirtiendo, cada día con mayor peso, en la clave del éxito competitivo de las empresas, por lo que su identificación, medición y evaluación es un campo de estudio cada vez más relevante desde el punto de vista de la Dirección de Empresas».

Lev (2003: 21) define el término «activos intangibles» como un sinónimo de "capital intelectual $»^{2}$ para referirse a fuentes generadoras de valor que carecen de sustancia física, y son generados por medio de la innovación, diseños organizativos únicos o prácticas de gestión de los recursos humanos.

1. Los autores citan a Itami, H. (1987). Mobilizing Invisible Assets. Cambridge, Mass.: Harvard University Press.

2. Lev (2003:20) emplea los términos «intangibles», "conocimiento» y «capital intelectual» de manera indistinta; aunque en la presente investigación se hará una distinción en el concepto de " «conocimiento". 
Para gestionar el capital intelectual; es decir, para crear, adquirir, desarrollar o explotar activos intangibles, diversos autores han propuesto diferentes modelos, los que se presentan en el cuadro 1.

\section{Cuadro 1}

\section{Modelos de gestión de Capital Intelectual}

\begin{tabular}{|llr|}
\hline \multicolumn{1}{|c}{ Modelo } & \multicolumn{1}{c|}{ Autores } & Año \\
\hline Balanced Scorecard & Kaplan y Norton & 1992 \\
Technology Broker & Brooking & 1996 \\
Navigator de Skandia & Edvinsson & 1997 \\
Intellectual Assets Monitor & Sveiby & 1997 \\
Intelect & Euroforum & 1998 \\
Dirección por competencias & Bueno & 1998 \\
\hline
\end{tabular}

Fuente: elaboración propia

Si se analizan los modelos de medición de capital intelectual citados, todos comparten o incluyen muchos elementos comunes; inclusive, pueden considerarse que algunos modelos representan una evolución o una versión más moderna de otros. De todos estos modelos, quizá el modelo Intelect de Euroforum representa hoy el de mayor aceptación y consenso hoy Por ejemplo, el modelo BSC de Kaplan y Norton, alineado al modelo Intelect, considera que la perspectiva de «aprendizaje y crecimiento» está conformada por el capital humano, el capital estructural y el capital relacional.

La Fundación Iberoamericana del Conocimiento ${ }^{3}$ define el modelo Intelect como una herramienta que permite identificar, seleccionar, estructurar y medir los activos intangibles. Por lo tanto, el modelo ofrece información relevante para la toma de decisiones, para analizar la capacidad de la organización de generar resultados sostenibles, para mejorar constantemente y crecer a largo plazo, y para estimar el valor de la empresa.

Asimismo, en la Fundación La Fundación Iberoamericana del Conocimiento se señalan las siguientes características del modelo:
- Modelo de capital intelectual que se enlaza con la estrategia empresarial.

- Modelo personalizado a cada organización.

- Modelo abierto y flexible.

- Medición no solo de resultados sino también de los procesos que los generan.

- Visión sistémica del modelo.

- Aplicabilidad del modelo.

- Combina distintas unidades de medida.

En relación con la estructura del modelo, Intelect se estructura en bloques, elementos e indicadores ${ }^{4}$ :

a) Bloques

Agrupación de activos intangibles en función de su naturaleza. Según el modelo, los activos intangibles se clasifican en tres grandes bloques:

- Capital humano. Está referido al recurso que constituyen las personas que conforman la organización, al conocimiento explícito y tácito de ellas y la capacidad de generar valor del personal.

- Capital estructural. Es el conocimiento y los activos intangibles definidos, sistematizados e internacionalizados en la organización. A diferencia del anterior, el capital estructural es de propiedad e inherente a la institución, aun cuando algunas personas dejen de trabajar en la organización.

- Capital relacional. Está referido al conjunto de activos intangibles que se derivan de la relación de la institución con los clientes y proveedores o, en general, con cualquier otro agente externo.

b) Elementos

Activos intangibles que corresponden a cada bloque (en el gráficol se muestran los elementos de cada uno de los tres bloques). Cada organización debe elegir los elementos más relevantes en función de su estrategia y los factores críticos de éxito.

3. Fuente: <http://www.gestiondelconocimiento.com>.

4. Fuente: <http://www.gestiondelconocimiento.com>. 


\section{Gráfico 1}

\section{Modelo «Intelect» (Euroforum)}

\begin{tabular}{|c|c|c|c|}
\hline \multicolumn{4}{|c|}{ Capital Intelectual } \\
\hline \multirow{13}{*}{ 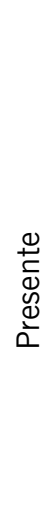 } & Capital humano & Capital estructural & Capital relacional \\
\hline & Satisfacción personal & Cultura y Filosofía & Base de datos clientes \\
\hline & Estructura personal & Procesos reflexión estrat. & Lealtad clientes \\
\hline & Competencias & Estructura organizacional & Relación clientes \\
\hline & Liderazon & Propiedad intelectual & Satisfacción clientes \\
\hline & Estahilidad & Tecnología de proceso & Proc. apoyo/servicio cliente \\
\hline & Estadildad & Tecnología de producto & Cercanía al mercado \\
\hline & & Procesos de apoyo & Notoriedad de marca \\
\hline & & Procesos captación & Reputac. nombre empr. \\
\hline & & conocimiento & Alianzas estratégicas \\
\hline & & Mecanismos & Interrelación proveedores \\
\hline & & Comunicación & Interrelación otros agentes \\
\hline & & Tecnología información & \\
\hline \multirow{2}{*}{ 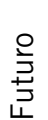 } & Mejora competencia & Proceso de innovación & Capacidad de mejora \\
\hline & Capacidad innovación & & Recreac. base datos clientes \\
\hline
\end{tabular}

Fuente: elaboración propia a partir de Euroforum ${ }^{5}$

c) Indicadores

Son la forma de medir o evaluar los elementos. Cada organización debe elegir los indicadores que le permiten medir los elementos críticos dentro de cada bloque.

\section{La gestión del conocimiento}

Von Krogh et al. (2001: 6-9) resaltan tres ideas básicas acerca del concepto «conocimiento»:

- El conocimiento es una certeza justificada: el conocimiento es una construcción de la realidad más que algo cierto en sentido abstracto 0 universal.

- El conocimiento es tanto explícito como tácito: en el sentido que algunos conocimientos son susceptibles de escribirse (explícito), mientras que otros son muy difíciles de describir (tácito).

- La eficaz creación de conocimiento depende de un contexto propicio, un espacio común en el que se fomenta el establecimiento de rela- ciones y este contexto de organización que puede ser físico, virtual o mental. En este sentido, el conocimiento está implícito en el ba (concepto japonés de «lugar»), a diferencia de la información o los datos que no dependen de un contexto.

Por su parte, Davenport (1999: 8-9) define y diferencia los términos datos, información y conocimiento, aunque considera que en la práctica no es sencillo separarlos y que es posible construir un continuo de los tres. Según el autor, los datos son observaciones de los estados del mundo, son fáciles de capturar, comunicar y almacenar; la información son «datos dotados de pertinencia y propósito» ${ }^{6}$; mientras que el conocimiento es información con mayor valor, que alguien le ha dado el contexto informativo, el significado o la interpretación particular y ha reflexionado y agregado su propia sabiduría. Asimismo, en el cuadro 2 se muestra cómo el autor esquematiza estas diferencias. 


\section{Cuadro 2}

\section{Datos, información y conocimiento}

\begin{tabular}{|c|c|c|}
\hline Datos & Información & Conocimiento \\
\hline $\begin{array}{l}\text { Observaciones sencillas de los } \\
\text { estados del mundo. } \\
\text { - Se estructuran fácilmente. } \\
\text { - Se capturan con facilidad } \\
\text { en las máquinas. } \\
\text { - A menudo se cuantifican. } \\
\text { - Se transfieren con } \\
\text { facilidad. }\end{array}$ & $\begin{array}{l}\text { Datos dotados de pertinencia y } \\
\text { propósito } \\
\text { - Requiere una unidad de } \\
\text { análisis. } \\
\text { - Necesita consenso sobre el } \\
\text { significado. } \\
\text { - La intermediación humana es } \\
\text { indispensable. }\end{array}$ & $\begin{array}{l}\text { Información valiosa de la } \\
\text { mente humana. Incluye } \\
\text { reflexión, síntesis y contexto } \\
\text { - Difícil de estructurar. } \\
\text { - Difícil de capturar en las } \\
\text { máquinas. } \\
\text { - A menudo es tácito. } \\
\text { - La transferencia es complicada. }\end{array}$ \\
\hline
\end{tabular}

Fuente: Davenport 1999: 8

Para gestionar el conocimiento, en primer lugar, se debe identificar el tipo de conocimiento que se desea gestionar, pues las acciones más pertinentes dependen de esta clasificación. Al respecto, la clasificación más frecuente es tipificar el conocimiento como tácito o explícito.

- El conocimiento tácito es el conocimiento implícito que utilizan los miembros de una organización para realizar su trabajo y que no está codificado, es difícil de difundir y es difícil de expresar verbalmente, porque se manifiesta en destrezas que se basan en acciones y no pueden reducirse a reglas y recetas (Choo 1999: 136). Choo también comenta, citando el trabajo de Polanyi (1962: 4 y 49, respectivamnete), que dicho autor hace referencia al conocimiento tácito cuando argumentar que "podemos saber más de lo que podemos decir» y que «el propósito de una ejecución diestra se logra mediante la observancia de una serie de reglas que la persona que las sigue no conoce como tales».

- El conocimiento explícito es el conocimiento que se puede expresar formalmente, comunicarse o difundirse con facilidad. Choo (1999: 133), quien cita a Nonaka y Takeuchi (1995) cuando presenta la definición, considera que el conocimiento explícito puede codificarse ya sea mediante símbolos (palabras, números, fórmulas), objetos físicos (dibujos técnicos, prototipos, fotos, etcétera) o reglas (manual de procedimientos, normas, etcétera).
Con relación a los procesos de creación de conocimiento, aunque varios autores han planteado modelos de generación de conocimientos, el modelo de Nonaka y Takeuchi (1999) es el de mayor difusión en el ámbito académico. Según Nonaka y Takeuchi (1999: 68), mediante la interacción y conversión entre conocimiento tácito y explícito, hay cuatro modos de crear conocimiento en las organizaciones: socialización, exteriorización, combinación e interiorización (proceso CECI). Además, dado que la creación del conocimiento requiere de un espacio concreto, surge el concepto de $B a$, que significa el espacio compartido donde se producen las interacciones del conocimiento. Así, de acuerdo con el tipo de proceso $\mathrm{CECl}$ que se lleve a cabo, existen cuatro tipos de $\mathrm{Ba}$ (véase el gráfico 2). A continuación, se detallan los procesos $\mathrm{CECl}$ :

\section{- Combinación}

Es el proceso de generar conocimientos explícitos a partir de conocimientos explícitos. Esta es una forma común de transferir conocimiento mediante la combinación o el reordenamiento de documentos o por la reestructuración de conocimientos anteriormente explicitados. El proceso se desarrolla en el denominado $\mathrm{Ba}$ sistematizador.

\section{- Exteriorización}

Es el proceso fundamental de creación del conocimiento, en el cual el conocimiento tácito logra explicitarse al compartirse metáforas, analogías, modelos 0 anécdotas. El proceso se lleva a cabo en el denominado Ba dialogante. 


\section{Gráfico 2}

\section{Modelo de creación de conocimiento}

\begin{tabular}{|c|c|c|c|}
\hline & & \multicolumn{2}{|c|}{ CONOCIMIENTO GENERADO } \\
\hline & & CONOCIMIENTO EXPLÍCITO & CONOCIMIENTO TÁCITO \\
\hline \multirow{2}{*}{$\begin{array}{l}0 \\
R \\
\text { I } \\
G \\
E \\
N\end{array}$} & $\begin{array}{l}\text { CONOCIMIENTO } \\
\text { EXPLÍCITO }\end{array}$ & $\begin{array}{c}\text { COMBINACIÓN } \\
\text { («Ba» sistematizador) }\end{array}$ & $\begin{array}{l}\text { INTERIORIZACIÓN } \\
\text { («Ba» operativo) }\end{array}$ \\
\hline & $\begin{array}{c}\text { CONOCIMIENTO } \\
\text { TÁCITO }\end{array}$ & $\begin{array}{l}\text { ESTERIORIZACIÓN } \\
\text { («Ba» dialogante) }\end{array}$ & $\begin{array}{l}\text { SOCIALIZACIÓN } \\
\text { («Ba» originario) }\end{array}$ \\
\hline
\end{tabular}

Fuente: Elaboración propia a partir de Nonaka y Takeuchi (1999).

- Socialización

Es el proceso de compartir experiencias que crean conocimientos tácitos a partir de otros conocimientos tácitos, como los modelos mentales y las habilidades técnicas. Con frecuencia, el proceso de socialización se da cuando los aprendices observan, ayudan o imitan al personal más experimentado. Este proceso se desarrolla en el denominado $\mathrm{Ba}$ originario.

- Interiorización

Es el proceso de aprender por medio de la ejecución reiterada de una tarea, de modo que el conocimiento explícito de los principios y procedimientos sea absorbido como el conoci- miento tácito del estilo y el hábito del individuo. El proceso se desarrolla en el denominado Ba operativo.

\section{Metodología de la investigación}

El presente estudio representa un ensayo de corte científico que, a partir del marco teórico y la información obtenida de entrevistas en profundidad con investigadores, analiza y propone la forma de aplicar la gestión de procesos en un centro de investigación universitario, mediante la incorporación de la gestión del capital intelectual y la gestión del conocimiento. En el cuadro 3 se presenta la metodología propuesta.

\section{Cuadro 3}

\section{Metodología de investigación propuesta}

\begin{tabular}{|l|l|l|}
\hline & & \multicolumn{1}{|c|}{ Fuentes de información / Metodología } \\
\hline Fase 1 & Gestión de procesos & $\begin{array}{l}\text { Entrevistas en profundidad con investigadores y aplicación } \\
\text { de la gestión de procesos basada en calidad a un centro de } \\
\text { investigación. }\end{array}$ \\
\hline Fase 2 & $\begin{array}{l}\text { Gestión de procesos } \\
\text { incorporando la gestión del } \\
\text { capital intelectual }\end{array}$ & $\begin{array}{l}\text { Entrevistas en profundidad y aplicación del marco teórico } \\
\text { «capital intelectual» a un centro de investigación, a partir } \\
\text { del modelo de gestión de procesos basado en calidad. }\end{array}$ \\
\hline Fase 3 & $\begin{array}{l}\text { Gestión de procesos } \\
\text { incorporando la gestión el } \\
\text { conocimiento }\end{array}$ & $\begin{array}{l}\text { Entrevistas en profundidad y aplicación del marco teórico } \\
\text { gestión del conocimiento a un centro de investigación, a } \\
\text { partir del modelo de gestión de procesos basado en calidad. }\end{array}$ \\
\hline
\end{tabular}


Se realizaron dos entrevistas en profundidad con investigadores que han desempeñado el cargo de directores de centros de investigación de universidades y seis entrevistas en profundidad con profesores-investigadores del Centro de Investigación de la Universidad del Pacífico (CIUP). Sin embargo, las preguntas no estuvieron orientadas a evaluar o definir los procesos del CIUP, sino a definir la forma más adecuada de gestionar un centro de investigación, cualquiera que sea la universidad.

\section{Aplicación de la metodología}

Fase 1: Gestión de procesos

De acuerdo con el marco teórico presentado, a continuación se detalla la gestión de procesos bajo un enfoque de calidad aplicado a un centro de investigación.

a) Identificar los atributos valorados de la investigación

Respecto de los atributos o características valoradas de un centro de investigación, las principales conclusiones de las dos entrevistas realizadas con los investigadores que desempeñaron el cargo de directores de centros de investigación de universidades fueron las siguientes:

- El atributo más valorado corresponde al reconocimiento académico o reputación del investigador. Si una obra es escrita por un líder de opinión en el tema, esta será leída con interés por otros profesionales y, a su vez, se convertirá en un insumo para otras investigaciones. Así, se forman un círculo virtuoso de generación de conocimientos.

- La calidad de los investigadores no solo está dada por la reputación del autor, sino también influye su grado académico.

- En cuanto a la producción en sí, un criterio que necesariamente debe tomarse en cuenta está referido a la cantidad de papers que son aceptados en revistas internacionales con arbitrajes muy estrictos.

- Uno de los aspectos más importantes de la investigación es el impacto que pueda lograr en la comunidad académica, en la sociedad y en la empresa. Al respecto, el término «impacto» puede concebirse como el grado de aplicación o uso que tenga la investigación.

- Otro punto importante es que la investigación debe generar nuevo conocimiento, medido a partir de la presencia de los resultados de la investigación en revistas o journals de reconocido prestigio internacional.

- La investigación no solo debe aportar conocimiento, también debe ser relevante y aplicable a situaciones diversas.

De igual forma, los investigadores entrevistados identificaron los siguientes atributos valorados de la investigación:

- Las actividades de investigación deben generar fondos para continuar o ampliar estudios.

- La investigación debe estar alineada a las líneas de investigación del centro de investigación al que pertenece.

- El marco teórico de la investigación tiene que estar basado en el «estado del arte» del conocimiento, en la llamada «frontera» del conocimiento.

- Los objetivos de la investigación deben ser claros y deben guardar una estrecha relación con los resultados de la investigación.

- La estructura o secuencia del documento debe ser adecuada.

- La metodología debe ser pertinente.

- El documento debe tener una buena redacción.

Teniendo presente esta información, es posible identificar los atributos valorados y agrupados en bloques 0 «elementos de calidad». Nótese también que esta información contiene tanto atributos de calidad inherentes a la investigación en sí, como variables clave: la reputación del investigador, el grado académico, la presencia en journals académicos y la capacidad de generar recursos financieros. Estos últimos elementos, que corresponden al enfoque de capital intelectual, no serán considerados en el enfoque de calidad porque esta perspectiva solo incluye atributos percibidos por el cliente, no elementos o factores internos de la organización. 
En el gráfico 3 se esquematizan los atributos de calidad identificados:

\section{Gráfico 3}

\section{Atributos valorados de la investigación}
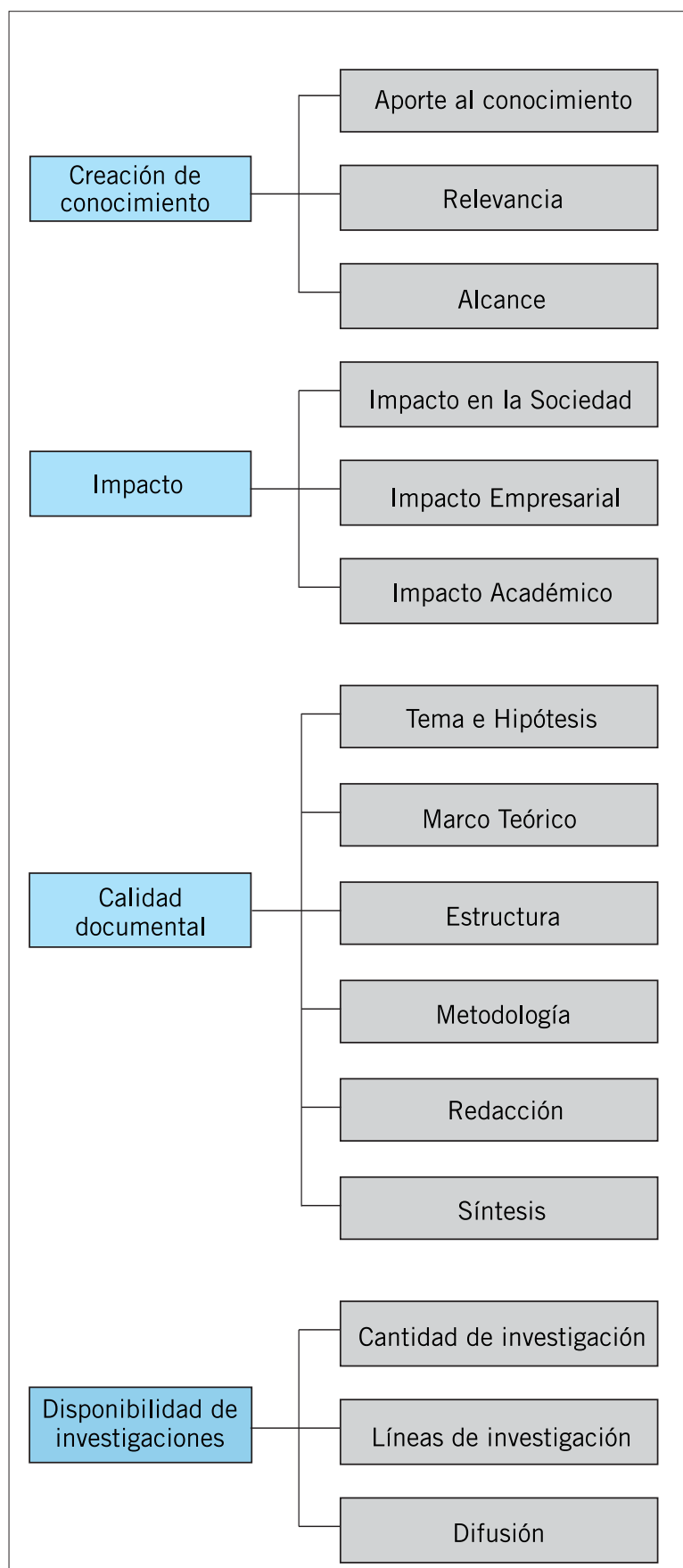

\section{Descripción}

Generación de conocimientos, teorías o modelos.

Tema de interés, que permita resolver cuestiones en la sociedad o ámbito de estudio

Aplicable a múltiples situaciones, capacidad de generalizar resultados

Solución a problemas del país o a un ámbito social específico

Aplicable a empresas, solución a problemas de las empresas

Aporte al mundo académico, usado para nuevas investigaciones 0 en actividades lectivas

Objetivos claramente definidos, idoneidad de la hipótesis y vínculo con los resultados

Pertinente y suficiente marco teórico, dominio teórico del tema de estudio

Estructura de capítulos, secuencia lógica y pertinente de capítulos

Metodología pertinente y válida para sustentar resultados, rigurosidad científica

Calidad de la redacción y estilo; facilidad de lectura y comprensión

Capacidad de síntesis y claridad de conclusiones y recomendaciones

Volumen total de investigaciones del Centro

Cantidad de investigaciones por línea, balance entre las líneas de investigación

Conocimiento de existencia de publicación y acceso a la publicación

Fuente: Elaboración propia 
b) Identificar los atributos críticos de la investigación

En las entrevistas con los investigadores, también se indagó acerca de los atributos críticos para la gestión de calidad de los centros de investigación.

Para evaluar los atributos críticos no se empleó una encuesta de satisfacción de clientes, dado que el presente estudio no tiene como objetivo evaluar la calidad de un centro de investigación en particular, sino hacer un sondeo cualitativo acerca de los factores más relevantes para la gestión de procesos de los centros de investigación. Nótese que al obtener información de los investigadores, se está partiendo de la premisa que ellos tienen suficiente conocimiento de los atributos valorados de la investigación.
Al respecto, a continuación se presenta la clasificación de los atributos críticos para la gestión de calidad de los centros de investigación":

- Alcance de la investigación

- Impacto empresarial

- Impacto académico

- Aporte al conocimiento

- Relevancia.

c) Identificar y elaborar un mapeo de procesos Para identificar y elaborar un mapa de procesos, en las entrevistas también se definieron los procesos que normalmente realizan los investigadores. A partir de la lista de procesos elaborada, en el gráfico 4 se muestra el mapa de procesos. En él, no solo se pueden visualizar los procesos, además se representan las principales interacciones entre ellos.

\section{Gráfico 4}

\section{Mapeo de procesos}

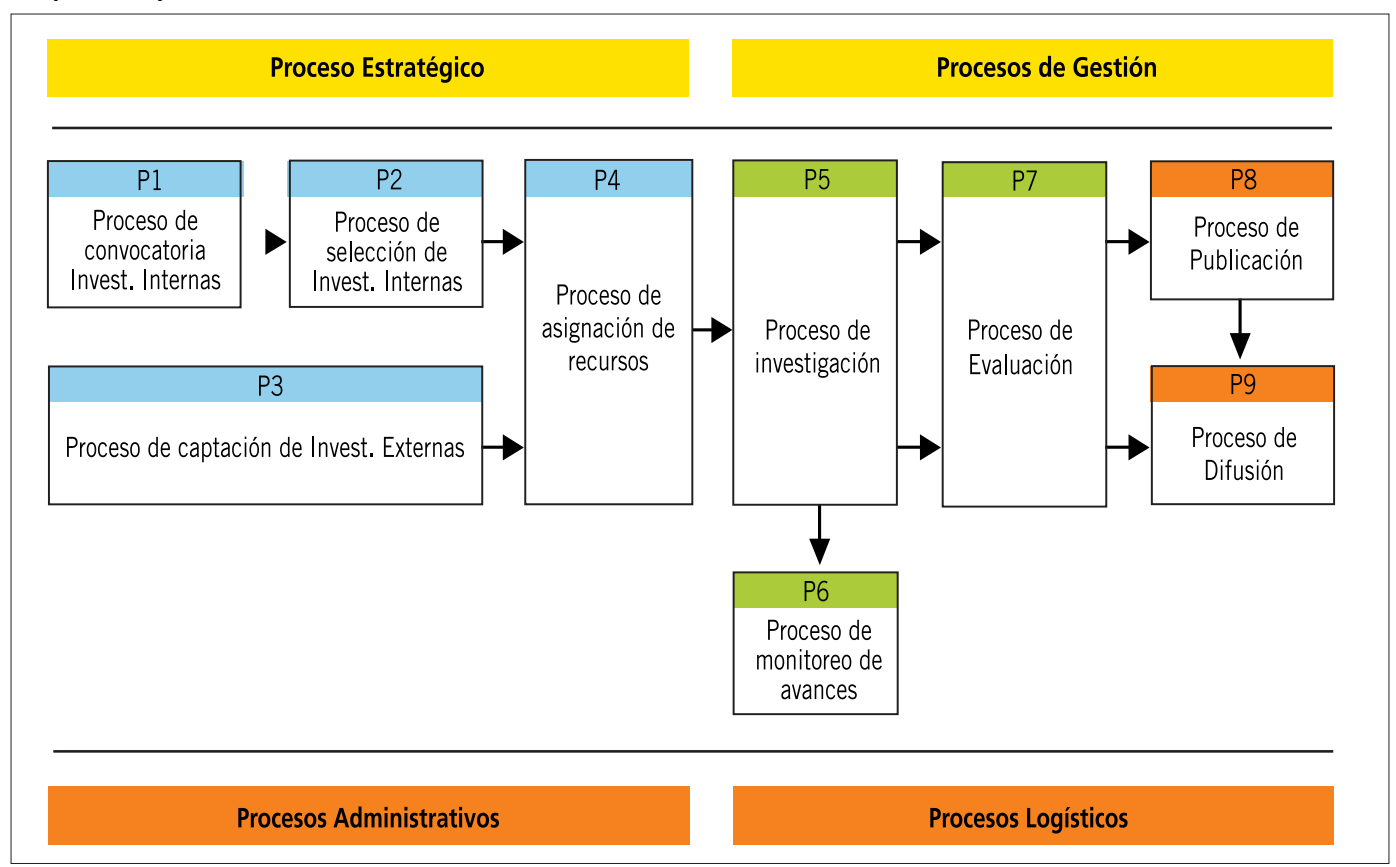

Elaboración propia.

7. Para establecer la clasificación de atributos, se solicitó a los entrevistados que evalúen, en una escala del 1 al 5 , la importancia de cada atributo para la gestión de calidad de los centros de investigación universitarios. 
Asimismo, se describió brevemente cada uno de los actuales procesos:

\section{P1 Proceso de convocatoria de investigaciones internas}

Las investigaciones internas se refieren a los estudios con fuente de financiamiento interna; es decir, aquellas investigaciones asumidas económicamente por la universidad.

\section{P2 Proceso de selección de investigaciones in- ternas}

Se recepcionan, evalúan y seleccionan las propuestas de investigación presentadas por los investigadores, de acuerdo con algunos criterios básicos, como la cantidad total de investigaciones en función de un límite presupuestal pre-establecido, el balance de las líneas de investigación, el número máximo de investigaciones por profesor, el desempeño anterior de los investigadores, la relevancia del tema y calidad de la propuesta, entre otros.

\section{P3 Proceso de captación de investigaciones ex- ternas}

Las investigaciones externas se refieren a los estudios con fuentes de financiamiento externas; es decir, aquellas investigaciones asumidas económicamente por otras instituciones. Por lo general, estas investigaciones son el resultado de las gestiones individuales de los investigadores para conseguirlas.

\section{P4 Proceso de asignación de recursos}

Se refiere a la asignación de asistentes, recursos financieros, ambientes de trabajo, equipos y recursos en general a los proyectos; así como, a la parte administrativa y logística que corresponde a dichos recursos.

\section{P5 Proceso de investigación}

Corresponde al proceso de investigación en sí, realizado por los profesores en forma coordinada con los asistentes.

\section{P6 Proceso de monitoreo de avances}

Cuando el período de una investigación es mayor a seis meses, los investigadores presentan un avance de la investigación a la mitad del proyec- to. Normalmente, en esta etapa no se monitorea la calidad de la investigación, solo se hace un seguimiento del grado de avance para tratar de reducir el riesgo de incumplir con el plazo de entrega del documento final.

\section{P7 Proceso de evaluación}

Al final de la investigación, se evalúa si se cumplieron los objetivos de investigación, si los resultados y conclusiones están referidos al objeto de estudio, si la calidad de la investigación es adecuada, entre otros. Como resultado de la evaluación, se determina si la investigación es «publicable» 0 , en todo caso, se señalan las «observaciones» con el fin que sean subsanadas.

\section{P8 Proceso de publicación}

El proceso de publicación se realiza si la investigación fue evaluada como "publicable» y, además, si se tenía prevista dicha publicación. No todas las investigaciones son publicadas, ya sea por no cumplir los estándares mínimos o porque no fueron presupuestadas por alguna razón en particular.

\section{P9 Proceso de difusión}

Además de la publicación, que representa en sí una forma tradicional de difundir los resultados de una investigación, hay otras formas de difusión: las notas de prensa, los artículos que se elaboran para la comunidad académica, la transferencia de conocimientos al aula, la presentación de resultados en conferencias o en "desayunos empresariales», entre otros.

d) Realizar un análisis de valor de procesos e identificar los procesos críticos desde la perspectiva de calidad

Para analizar el valor de cada uno de los procesos, se utilizó una matriz que trata de identificar los procesos capaces de mejorar cada uno de los atributos valorados de la investigación. En este caso, se propone plantear la relación atributo-proceso de manera cualitativa. Cabe señalar que también se puede elaborar la matriz cuantitativamente, asignando puntajes según el impacto alto, medio o bajo del proceso, para mejorar cada atributo. 
Aunque esta técnica puede ser aplicada exclusivamente a los atributos críticos identificados, en el gráfico 5 se presenta el análisis de los procesos claves para cada uno de todos los atributos identificados.

Según este análisis, desde la perspectiva de calidad, se pueden identificar los siguientes procesos críticos:

\section{P2. Proceso de selección de investigaciones internas}

Establecer criterios de selección que permitan priorizar las investigaciones con un alto potencial en los atributos: alcance, impacto empresarial, impacto académico, aporte al conocimiento y relevancia.

\section{P3. Proceso de captación de investigaciones externas}

Orientar y priorizar esfuerzos para captar más investigaciones, sobre todo más «relevantes».

\section{P5. Proceso de investigación}

Orientar y desarrollar investigaciones con mejores resultados, en términos de los atributos: alcance, impacto empresarial, impacto académico, aporte al conocimiento y relevancia.

\section{P6. Proceso de monitoreo de avances}

Reforzar el monitoreo de avances de investigación, sobre todo verificar que se están cumpliendo los objetivos de impacto empresarial e impacto académico. Así, se podrán tomar las acciones correctivas pertinentes y a tiempo.

\section{P7. Proceso de evaluación}

Enfatizar la evaluación de la investigación en los criterios: alcance, impacto empresarial, impacto académico, aporte al conocimiento y relevancia, y dar la conformidad solo si se cumplen estos objetivos.

\section{P8. Proceso de publicación}

Publicar los resultados de la investigación resaltando sus impactos empresarial y académico.

\section{Gráfico 5}

Análisis de valor de los procesos

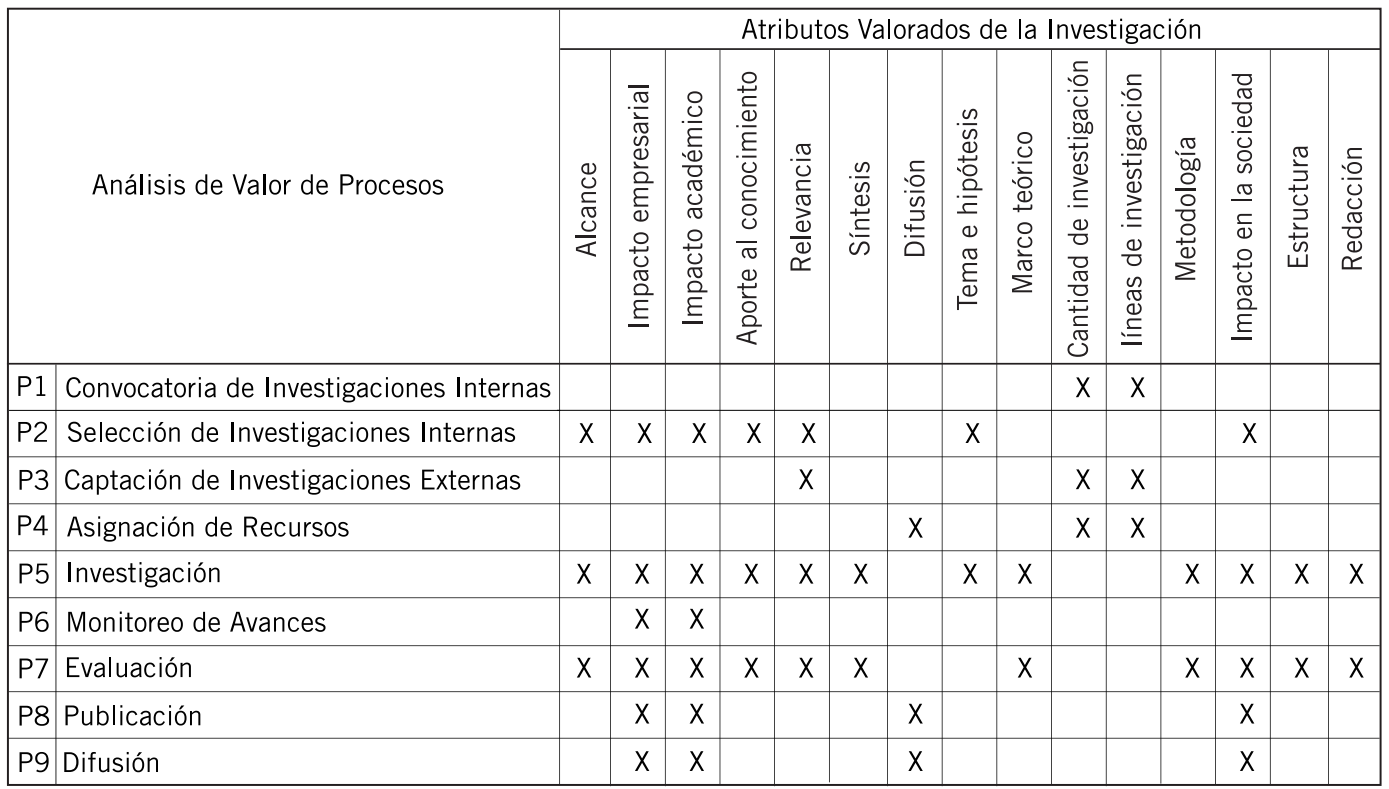

Elaboración propia 


\section{P9. Proceso de difusión}

Difundir en los medios y canales más adecuados para lograr un mayor impacto empresarial y académico.

e) Definir indicadores de gestión de procesos claves

Desde la perspectiva de calidad, una vez definidos los procesos críticos y los aspectos de mejora, se deben identificar los indicadores de gestión de procesos y proceder al análisis y el mejoramiento de procesos.

Sin embargo, de acuerdo con los objetivos de la investigación, este análisis no se planteará en el presente estudio. Solo a modo de ejemplo, a continuación se presentan los indicadores de gestión que podrían plantearse a «P5. Proceso de Investigación»:

- Porcentaje de satisfacción de calidad de investigación (informe de evaluación)

- Porcentaje de investigaciones observadas en la evaluación

- US\$/año facturados en consultorías generados por investigación

- $\mathrm{N}^{\circ}$ investigaciones/año que son aplicadas en empresas

- $\mathrm{N}^{\circ}$ investigaciones/año que generan aportes al conocimiento

- $N^{\circ}$ investigaciones/año que se utilizan en cursos

- $\mathrm{N}^{\circ}$ investigaciones/año presentes en journals

- Demanda anual promedio de publicaciones

- Informe de evaluación respecto de «Tema/ Hipótesis»

- Informe de evaluación con respecto a «Síntesis»

- Informe de evaluación con relación a «Metodología»

- Informe de evaluación «Marco teórico»

- Informe de evaluación «Redacción»

- Informe de evaluación «Estructura»

\section{Fase 2: Gestión de procesos incorporando la gestión de capital intelectual}

Según la metodología planteada, esta etapa consiste en aplicar el marco teórico referido al «capital intelectual» a un centro de investigación, a partir del modelo de gestión de procesos basado en calidad.

En un estudio realizado en la Universidad Autónoma de Madrid, dirigido por Bueno et al. (2001), el equipo de investigadores liderado por $\mathrm{E}$. Bueno definió una estructura de once indicadores de medición de capital intelectual en centros de investigación, estructurados en los tres bloques que plantea el modelo de gestión de capital intelectual «Intelect»:

- Capital humano: investigadores equivalentes tiempo completo; cualificación del investigador; incentivos a la investigación; personal auxiliar a tiempo completo.

- Capital estructural: recursos bibliográficos; recursos generadores de datos empíricos primarios; recursos generadores de datos empíricos secundarios; infraestructura básica de naturaleza intangible.

- Capital relacional: participación en reuniones científicas; pertenencia a sociedades científicas; colaboración con empresas y otras instituciones.

Sin embargo, el modelo propuesto puede complementarse con otros indicadores que pueden identificarse a partir de la revisión de cada bloque del modelo Intelect presentado en el marco teórico, así como las opiniones expresadas por los investigadores en las entrevistas realizadas. En los cuadros 4, 5 y 6 se presenta la lista de indicadores propuestos. 


\section{Cuadro 4}

\section{Detalle de indicadores de capital humano}

\begin{tabular}{|c|c|c|}
\hline \multicolumn{3}{|c|}{ BLOQUE 1: CAPITAL HUMANO } \\
\hline Elemento & Indicador & Detalle del indicador \\
\hline $\begin{array}{l}\text { Satisfacción del } \\
\text { personal }\end{array}$ & $\begin{array}{l}\text { Índice de motivación de } \\
\text { investigadores }\end{array}$ & $\begin{array}{l}\text { Grado de motivación de investigadores (encuesta), ya } \\
\text { sea por reconocimiento en el mundo académico, por } \\
\text { reducir el trabajo en otras labores, por obtener más in- } \\
\text { gresos económicos o por otros incentivos. }\end{array}$ \\
\hline \multirow{5}{*}{$\begin{array}{l}\text { Estructura del } \\
\text { personal }\end{array}$} & $\begin{array}{l}\text { Número de investigadores } \\
\text { equivalentes a tiempo completo }\end{array}$ & Cantidad total de investigadores equivalentes \\
\hline & $\begin{array}{l}\text { Investigadores/líneas de } \\
\text { investigación }\end{array}$ & $\begin{array}{l}\text { Cantidad promedio de investigadores por línea de in- } \\
\text { vestigación. }\end{array}$ \\
\hline & $\begin{array}{l}\text { Número mínimo de investigadores } \\
\text { por línea de investigación }\end{array}$ & $\begin{array}{l}\text { Balance de investigadores; distribución equitativa de } \\
\text { investigadores por líneas de investigación. }\end{array}$ \\
\hline & Asistentes/investigadores & $\begin{array}{l}\text { Ratio para medir el apoyo de personal a los inves- } \\
\text { tigadores. }\end{array}$ \\
\hline & $\begin{array}{l}\text { Record histórico de } \\
\text { investigaciones/investigador }\end{array}$ & $\begin{array}{l}\text { Experiencia como investigador: total de investigacio- } \\
\text { nes hechas a lo largo de su vida por investigador. }\end{array}$ \\
\hline \multirow{2}{*}{ Competencia } & Calificación de investigadores & $\begin{array}{l}\text { Calidad de los investigadores según informes de evalua- } \\
\text { ción internos. }\end{array}$ \\
\hline & $\%$ Doctores & $\begin{array}{l}\text { Porcentaje de investigadores que tienen el grado de } \\
\text { Doctor respecto al total de investigadores que publica- }\end{array}$ \\
\hline
\end{tabular}

Elaboración propia.

\section{Cuadro 5}

\section{Detalle de indicadores de capital estructural}

\begin{tabular}{|c|c|c|}
\hline \multicolumn{3}{|c|}{ BLOQUE 2: CAPITAL ESTRUCTURAL } \\
\hline Elemento & Indicador & Detalle del indicador \\
\hline \multirow{3}{*}{$\begin{array}{l}\text { Propiedad } \\
\text { intelectual }\end{array}$} & $\begin{array}{l}\text { Número de publicaciones } \\
\text { disponibles (libros) }\end{array}$ & $\begin{array}{l}\text { Número de publicaciones propias del centro que están } \\
\text { a disposición de los investigadores; investigaciones } \\
\text { pasadas que han sido publicadas en formato de libro } \\
\text { impreso. }\end{array}$ \\
\hline & $\begin{array}{l}\text { Número de investigaciones (base } \\
\text { de datos) }\end{array}$ & $\begin{array}{l}\text { Base de datos de investigaciones, internas y externas, } \\
\text { que no han sido publicadas; acceso a formato digital. }\end{array}$ \\
\hline & $\begin{array}{l}\text { Número de artículos (base de } \\
\text { datos) }\end{array}$ & $\begin{array}{l}\text { Base de datos de artículos (papers) de difusión de } \\
\text { resultados de investigaciones; acceso a formato digital. }\end{array}$ \\
\hline $\begin{array}{l}\text { Tecnología de } \\
\text { Información }\end{array}$ & $\begin{array}{l}\text { Número de papers (base de datos } \\
\text { internacionales) }\end{array}$ & $\begin{array}{l}\text { Acceso a base de datos internacionales (externa) en } \\
\text { formato digital. }\end{array}$ \\
\hline \multirow{2}{*}{$\begin{array}{c}\text { Procesos de } \\
\text { apoyo/Captación } \\
\text { de conocimientos }\end{array}$} & $\begin{array}{l}\text { Número de suscripciones en } \\
\text { revistas }\end{array}$ & $\begin{array}{l}\text { Número de revistas presentes en la hemeroteca; revistas } \\
\text { que la universidad recibe por estar suscritos. }\end{array}$ \\
\hline & Número de títulos en biblioteca & $\begin{array}{l}\text { Número de libros consultados (que no sean antiguos) } \\
\text { en la Biblioteca de la universidad. }\end{array}$ \\
\hline $\begin{array}{l}\text { Tecnología de } \\
\text { proceso }\end{array}$ & $\begin{array}{l}\text { Número de documentos y } \\
\text { manuales internos }\end{array}$ & $\begin{array}{l}\text { Documentos y manuales de consulta de metodología } \\
\text { de la investigación, mejores prácticas, etcétera. }\end{array}$ \\
\hline
\end{tabular}

Elaboración propia. 


\section{Cuadro 6}

Detalle de indicadores de capital relacional

\begin{tabular}{|c|c|c|}
\hline \multicolumn{3}{|c|}{ BLOQUE 3: CAPITAL RELACIONAL } \\
\hline Elemento & Indicador & Detalle del indicador \\
\hline \multirow{2}{*}{$\begin{array}{l}\text { Relación con } \\
\text { clientes }\end{array}$} & $\begin{array}{l}\text { US } \$ \text { / año de financiamiento ex- } \\
\text { terno }\end{array}$ & $\begin{array}{l}\text { Facturación total obtenida de fuentes externas de } \\
\text { financiamiento }\end{array}$ \\
\hline & $\begin{array}{l}N^{0} \text { instituciones investigaciones ex- } \\
\text { ternas }\end{array}$ & $\begin{array}{l}\text { Número de instituciones que financian investigaciones } \\
\text { externas }\end{array}$ \\
\hline $\begin{array}{l}\text { Lealtad de } \\
\text { clientes }\end{array}$ & \% instituciones de repetición & $\begin{array}{l}\% \text { de instituciones que han financiado más de una in- } \\
\text { vestigación }\end{array}$ \\
\hline \multirow{2}{*}{$\begin{array}{l}\text { Interrelación } \\
\text { otros agentes }\end{array}$} & $\begin{array}{l}\mathrm{N}^{\circ} \text { de redes } \\
\text { (comunidades) }\end{array}$ & $\begin{array}{l}\text { Número de redes o comunidades en las cuales los in- } \\
\text { vestigadores forman parte }\end{array}$ \\
\hline & $\begin{array}{l}\text { Número de eventos } \\
\text { (asistencia)/año }\end{array}$ & $\begin{array}{l}\text { Número de eventos en los que participan los investiga- } \\
\text { dores }\end{array}$ \\
\hline $\begin{array}{c}\text { Reputación } \\
\text { nombre empresa }\end{array}$ & $\begin{array}{l}\text { Nivel de reputación } \\
\text { (reconocimiento) }\end{array}$ & $\begin{array}{l}\text { Nivel de imagen y reputación; reconocimiento de la } \\
\text { sociedad medida por encuestas }\end{array}$ \\
\hline $\begin{array}{l}\text { Alianzas } \\
\text { estratégicas }\end{array}$ & Número de convenios & $\begin{array}{l}\text { Número de convenios que se mantienen activos con } \\
\text { otras instituciones para apoyar o realizar investigacio- } \\
\text { nes conjuntas. }\end{array}$ \\
\hline
\end{tabular}

Elaboración propia.

En resumen, se han identificado 22 activos intangibles relevantes que se presentan en el gráfico 6 .

\section{Gráfico 6}

Indicadores de gestión de capital intelectual en centros de investigación

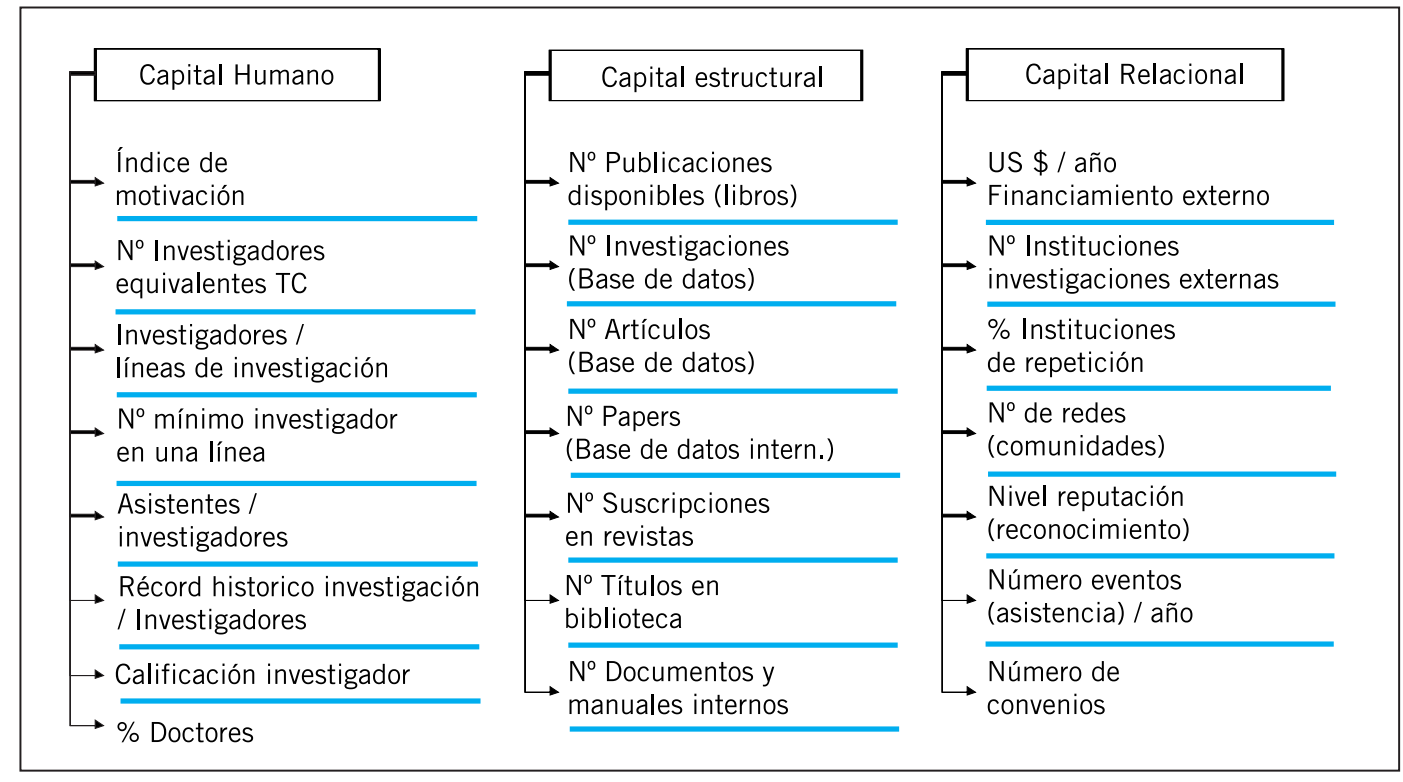

Elaboración propia 
En el cuadro 7 se identifican los procesos generadores de activos intangibles, con el propósito de incorporar esta visión a la gestión de procesos.

\section{Cuadro 7}

\section{Procesos generadores de activos intangibles}

\begin{tabular}{|l|l|l|}
\hline \multicolumn{2}{|c|}{ Indicadores de gestión de capital inta ngible } & Procesos generadores de activos intangibles \\
\hline H1 & Índice de motivación & Gestión de investigadores \\
H2 & Número de investigadores equivalentes TC & Gestión de investigadores \\
H3 & Investigadores/Líneas de investigación & Gestión de investigadores \\
H4 & Número mínimo de investigadores en una línea & Gestión de investigadores \\
H5 & Asistentes/Investigadores & Gestión de investigadores \\
H6 & Récord histórico investigaciones/Investigadores & Gestión de investigadores \\
H7 & Calificación de investigadores & Gestión de investigadores \\
H8 & \% de doctores & Gestión de investigadores \\
\hline E1 & Número de publicaciones disponibles (libros) & P8 + P9 Digitalización \\
E2 & Número de investigaciones (Base de datos) & P5 + Sistematización + Digitalización \\
E3 & Número de artículos (Base de datos) & P5 + Sistematización + Digitalización \\
E4 & Número de papers & Suministro de recursos externos \\
E5 & Número de suscripciones en revistas & Suministro de recursos externos \\
E6 & Números de títulos en biblioteca & Suministro de recursos externos \\
E7 & Número de documentos y manuales internos & Captación de mejores prácticas + elaboración \\
& & de documentos y manuales internos \\
\hline R1 & US\$/Año de financiamiento interno & Reforzar P3 \\
R2 & Número de instituciones investigaciones externas & Reforzar P3 \\
R3 & \% de instituciones de repetición & Reforzar P3 \\
R4 & Número de redes (comunidades) & Participación eventos + conformación redes y \\
R5 & Nivel de reputación (reconocimiento) & convenios \\
R6 & Número de eventos (asistencia)/Año & Reforzar P9 \\
R7 & Número de convenios & Participación eventos \\
& & Participación eventos + conformación redes y \\
\hline
\end{tabular}

Elaboración propia.

Como puede apreciarse, en el cuadro 7 se han presentado tanto los procesos que se encuentran definidos en la actualidad (codificación desde P1 hasta P9), como los que se han agregado de acuerdo con la función que deben realizar (por ejemplo, gestión de investigadores 0 digitalización). La ausencia de codificación de estos últimos puede deberse a que, en la actualidad, no se están realizando o se efectúan de manera informal.
Del análisis anterior, se puede argumentar que los nueve procesos actuales definidos de manera formal (enumerados desde P1 hasta P9) son insuficientes para gestionar los activos intangibles, sobre todo, si se desea enfatizar en los procesos generadores de dichos intangibles. Por ello, en la presente investigación se propone reestructurar el mapa de procesos, mediante la agregación de los procesos adicionales identificados como necesarios para la gestión del capital intelectual (véase el gráfico 7). 


\section{Gráfico 7}

\section{Mapeo de procesos incorporando la gestión del capital intelectual}

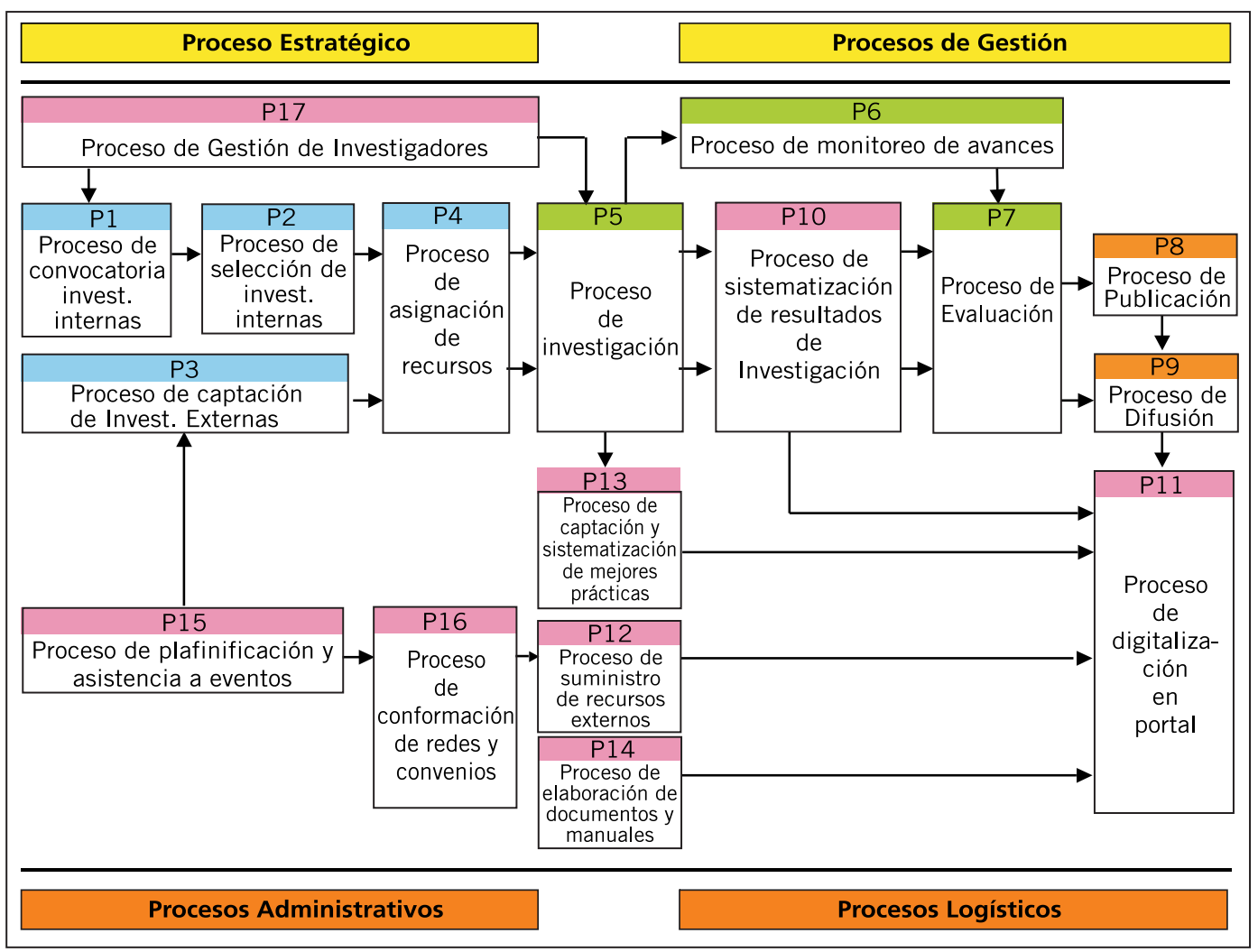

Elaboración propia.

A continuación, se detallan los nuevos procesos o «procesos de innovación»:

\section{P10. Proceso de sistematización de resulta- dos de investigación}

Además de elaborar el documento que corresponde a la investigación en sí, se propone que el investigador prepare un documento adicional que contenga un breve resumen o sumilla de la investigación; las palabras clave de la investigación; el resumen ejecutivo de resultados, en el que se detalle los principales hallazgos y conclusiones; entre otros. La elaboración de esta documentación será denominada como «Proceso de Sistematización de Resultados de Investigación». El volumen de investigaciones sistematizadas alimenta los siguientes indicadores de gestión de capital intelectual: E1 (Número de investigaciones publicadas en la base de datos), E2 (Número de investigaciones no publicadas en la base de datos) y E3 (Número de artículos en la base de datos).

\section{P11. Proceso de digitalización en portal}

Proceso de actualización permanente de un portal web de información y recursos del centro de investigación. El proceso consiste en recibir la documentación digital generada en los procesos P9, P10, P12, P13 y P14 e incorporarla en la web, con una estructura pertinente de links. Asimismo, se debe prever diferentes niveles de acceso, según los diferentes perfiles de usuarios (por ejemplo, los investigadores deben tener acceso a ciertos recursos no públicos). 


\section{P12. Proceso de suministro de recursos ex- ternos}

Proceso que consiste en coordinar y apoyar las labores que permiten que el centro incremente, de manera permanente, los recursos externos de apoyo a la investigación. Básicamente, este proceso puede enfocarse a las siguientes tres fuentes de recursos: (a) Búsqueda, identificación y acceso a bases de datos internacionales (acceso a papers en línea), que alimenta el indicador E4 (Número de papers en base de datos internacionales); (b) Búsqueda, identificación y suscripción de revistas relevantes para la investigación (coordinar y apoyar a la Hemeroteca de la universidad), que alimenta el indicador E5 (Número de suscripciones en revistas); (c) Búsqueda, identificación y compra de libros (Coordinar y apoyar a la Biblioteca de la universidad), que alimenta el indicador E6 (Número de títulos en biblioteca).

\section{P13. Proceso de captación y sistematización de mejores prácticas}

Proceso que consiste en fomentar y apoyar a los investigadores a compartir las «mejores prácticas» con los otros investigadores del centro. Este proceso constituye el canal por medio del cual los investigadores pueden realizar actividades para tratar de explicitar el aprendizaje que obtienen de la experiencia vivencial. Debido a los documentos que se generan en este proceso, se alimenta el indicador E7 (Número de documentos y manuales internos), aunque este no es el único proceso que genera dicho indicador (véase el proceso siguiente).

\section{P14. Proceso de elaboración de documentos y manuales}

Adicionalmente a la elaboración de documentos de «mejores prácticas» descrito en el proceso anterior, con este proceso se pretende elaborar documentos y manuales de carácter metodológico. Por ejemplo, se podrían elaborar documentos tipo «metodología de la investigación», «guía práctica de técnicas estadísticas», "guía de elaboración de encuestas», «manual de uso del software de procesamiento de datos», entre otros. Este proceso, en forma conjunta con el anterior, ali- menta el indicador E7 (número de documentos y manuales internos).

\section{P15. Proceso de planificación y asistencia a eventos}

La asistencia a eventos constituye hoy un elemento clave para mejorar el capital relacional, por lo que esta actividad no debe realizarse de manera informal; por el contrario, debe planificarse. Este es el espíritu del proceso, que los investigadores incrementen su red de contactos. Para ello, se requiere formalizar las actividades que permiten una mayor asistencia a eventos $y$ derivar más esfuerzos y control. Este proceso alimenta directamente al indicador R6 (Número de eventos: asistencia/año) y de manera indirecta al indicador R5 (Nivel de reputación). Además, este proceso es la fuente principal del proceso P16, de conformación de redes y convenios (véase el siguiente proceso, el cual alimenta los indicadores R4 y R7, y apoya fuertemente al proceso P3 (de captación de investigaciones externas). Por lo tanto, apoya en los indicadores R1, R2 y R3.

\section{P16. Proceso de conformación de redes y con- venios}

Proceso que consiste en conformar redes o comunidades de investigadores para intercambiar información o actividades en general. Así como, establecer convenios de colaboración mutua entre centros de investigación o con cualquier institución en general. Mediante este proceso se pretende que los investigadores incrementen su pertenencia a redes y comunidades, lo que alimenta el indicador R4 (Número de redes de pertenencia), y se apertura el canal de convenios interinstitucionales para realizar actividades conjuntas, lo que alimenta el indicador R7 (Número de convenios).

\section{P17. Proceso de gestión de investigadores}

Para poder implementar todas las acciones propuestas, primero, hace falta reforzar la «cultura de investigación» en los investigadores, mediante un conjunto de actividades, tales como: sensibilización de la importancia y rol de la investigación, fomento y promoción de la investigación, 
motivación a investigadores, sensibilización a compartir/transmitir conocimientos, entre otros. A pesar de que estas actividades se realizan transversalmente en la universidad, en este estudio se propone reforzar específicamente la gestión de los investigadores. En este sentido, este proceso alimenta los indicadores del bloque capital humano (indicadores desde $\mathrm{H} 1$ hasta $\mathrm{H} 8$ ).

De igual forma, de acuerdo con el análisis anteriormente presentado acerca de los procesos que originan 0 «alimentan» los indicadores, en el cuadro 8 se resume la forma cómo los indicadores de capital intelectual deben transferirse a los indicadores de procesos.

\section{Fase 3: Gestión de procesos incorporando la gestión del conocimiento}

Según la metodología planteada, esta etapa consiste en aplicar el marco teórico referido a la gestión del conocimiento a un centro de investigación, a partir del modelo de gestión de procesos basado en calidad.

De acuerdo con el análisis anteriormente efectuado acerca de los intangibles y los procesos de su generación, se pueden identificar y estructurar actividades de creación, captación y transmisión de conocimientos según el esquema ${ }^{8}$ presentado en el cuadro 9.

\section{Cuadro 8}

\section{Transmisión de indicadores de capital intelectual a los indicadores de procesos}

\begin{tabular}{|c|c|c|}
\hline \multicolumn{2}{|r|}{ Procesos } & \multirow{2}{*}{$\begin{array}{l}\quad \text { Indicadores de capital intelectual incluidos } \\
\text { E1: Número de investigaciones publicadas en base de datos } \\
\text { E2: Número de investigaciones no publicadas en base de } \\
\text { datos } \\
\text { E3: Número de artículos en la base de datos }\end{array}$} \\
\hline P10 & $\begin{array}{l}\text { Proceso de sistematización de } \\
\text { resultados de investigación }\end{array}$ & \\
\hline P11 & Proceso de digitalización en portal & $\begin{array}{l}\text { Número de documentos digitalizados, generados en los } \\
\text { procesos } \mathrm{P} 9, \mathrm{P} 10, \mathrm{P} 12, \mathrm{P} 13 \text { y } \mathrm{P} 14\end{array}$ \\
\hline P12 & $\begin{array}{l}\text { Proceso de suministro de recursos } \\
\text { externos }\end{array}$ & $\begin{array}{l}\text { E4: Número de papers (Base de datos internacionales) } \\
\text { E5: Número de suscripciones en revistas } \\
\text { E6: Número de títulos en biblioteca }\end{array}$ \\
\hline P13 & $\begin{array}{l}\text { Proceso de captación y sistematización } \\
\text { de mejores prácticas }\end{array}$ & E7: Número de documentos generados \\
\hline P14 & $\begin{array}{l}\text { Proceso de elaboración de documentos } \\
\text { y manuales }\end{array}$ & E7: Número de documentos y manuales internos \\
\hline P15 & $\begin{array}{l}\text { Proceso de planificación y asistencia a } \\
\text { eventos }\end{array}$ & $\begin{array}{l}\text { R6: Número de eventos: Asistencia/año } \\
\text { R5: Aporte en incremento de reputación }\end{array}$ \\
\hline P16 & $\begin{array}{l}\text { Proceso de conformación de redes y } \\
\text { convenios }\end{array}$ & $\begin{array}{l}\text { R4: Número de redes de pertenencia } \\
\text { R7: Número de convenios }\end{array}$ \\
\hline P17 & Proceso de gestión de investigadores & $\begin{array}{l}\text { H1: Índice de motivación } \\
\text { H2: Número de investigadores equivalentes a TC }\end{array}$ \\
\hline & & $\begin{array}{l}\text { H3: Investigadores/Líneas de investigación } \\
\text { H4: Número mínimo de investigadores en una línea } \\
\text { H5: Asistentes/Investigadores } \\
\text { H6: Récord histórico investigaciones/Investigaciones } \\
\text { H7: Calificación de investigadores } \\
\text { H8: \% de doctores }\end{array}$ \\
\hline P3 & $\begin{array}{l}\text { Captación de investigaciones externas } \\
\text { (proceso anteriormente definido) }\end{array}$ & $\begin{array}{l}\text { R1: US\$/año financiamiento externo (ya propuesto) } \\
\text { R2: No instituciones investigaciones externas } \\
\text { R3: \% instituciones de repetición }\end{array}$ \\
\hline
\end{tabular}

Elaboración propia

8. La mayoría de estas actividades fueron propuestas en el focus group con los investigadores. 


\section{Cuadro 9}

Actividades de creación, captación y transmisión de conocimientos

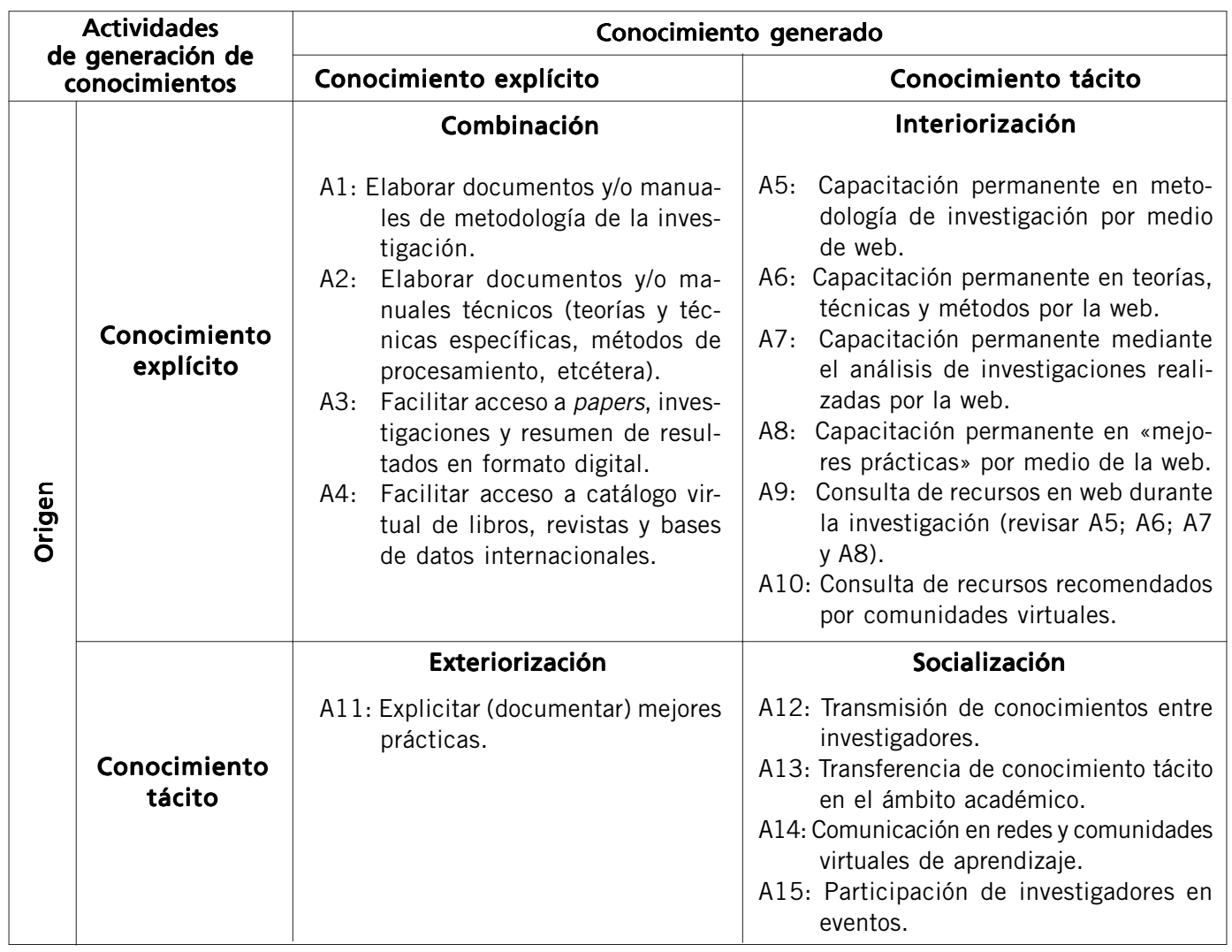

Elaboración propia

Asimismo, es posible plantear estrategias de generación de conocimientos para implementar las quince actividades de generación de conocimientos planteadas (véase el cuadro 10). Se proponen estrategias de acuerdo con las relaciones entre conocimiento tácito y explícito.
Si se analizan las actividades de generación de conocimiento en comparación con los procesos que se definieron anteriormente, la asignación más adecuada de actividades se muestra en el cuadro 11. 


\section{Cuadro 10}

\section{Estrategias para implementar las actividades de}

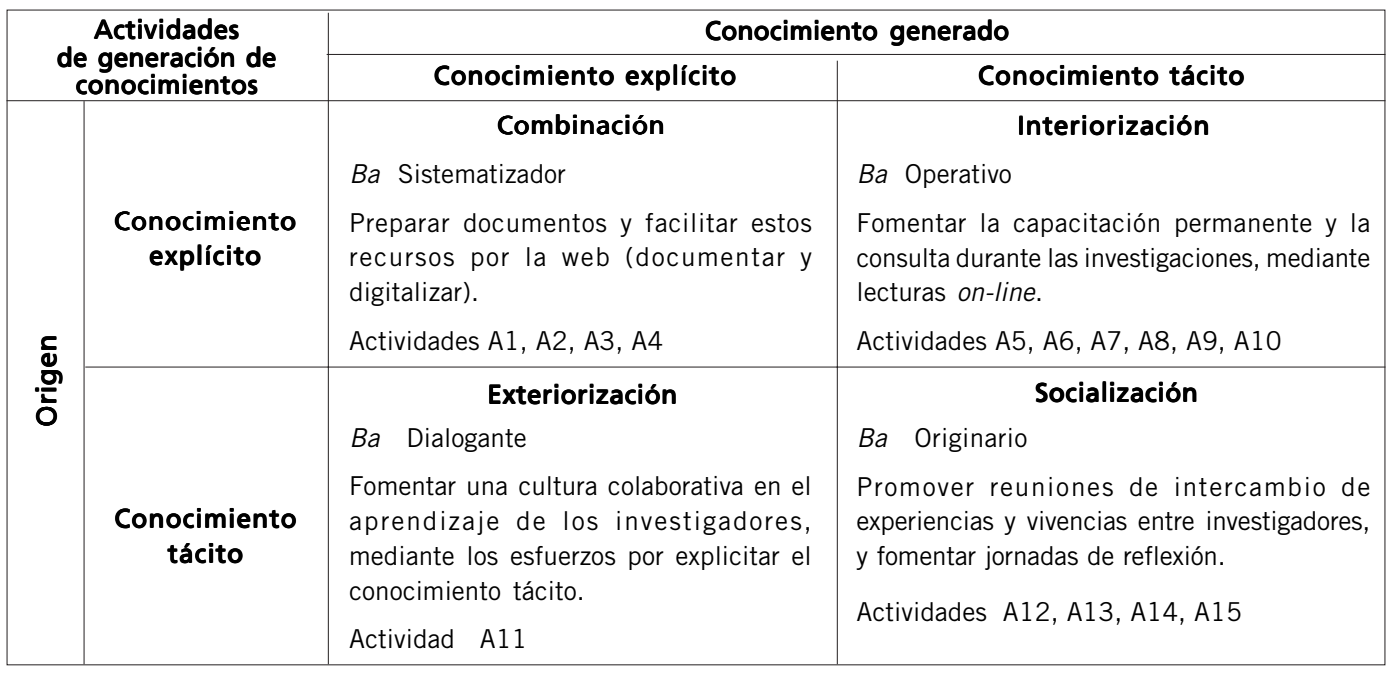

Elaboración propia.

\section{Cuadro 11}

Incorporación de actividades de generación de conocimientos a los procesos

\begin{tabular}{|c|c|c|}
\hline \multicolumn{2}{|r|}{ Procesos } & Actividades de generación de conocimientos \\
\hline P10 & $\begin{array}{l}\text { Proceso de sistematización de } \\
\text { resultados de investigación }\end{array}$ & $\begin{array}{l}\text { A3: Facilitar acceso a papers, investigaciones y resumen de resultados } \\
\text { en formato digital. }\end{array}$ \\
\hline P11 & Proceso de digitalización en portal & Digitalizar resultado de actividades: $A 1, A 2, A 3, A 4$, y $A 11$. \\
\hline P12 & $\begin{array}{l}\text { Proceso de suministro de recursos } \\
\text { externos }\end{array}$ & $\begin{array}{l}\text { A4: Facilitar acceso a catálogo virtual de libros, revistas y bases de datos } \\
\text { internacionales. }\end{array}$ \\
\hline P13 & $\begin{array}{l}\text { Proceso de captación y sistematiza- } \\
\text { ción de mejores prácticas }\end{array}$ & A11: Explicitar (documentar) mejores prácticas. \\
\hline P14 & $\begin{array}{l}\text { Proceso de elaboración de documen- } \\
\text { tos y manuales }\end{array}$ & $\begin{array}{l}\text { A1: Elaborar documentos y/o manuales de metodología de la investigación. } \\
\text { A2: Elaborar documentos y/o manuales técnicos (teorías y técnicas } \\
\text { específicas, métodos de procesamiento, etcétera). }\end{array}$ \\
\hline P15 & $\begin{array}{l}\text { Proceso de planificación y asistencia } \\
\text { a eventos }\end{array}$ & A15: Participación de investigadores en eventos. \\
\hline P16 & $\begin{array}{l}\text { Proceso de conformación de redes y } \\
\text { convenios }\end{array}$ & A14: Comunicación en redes y comunidades virtuales de aprendizaje. \\
\hline P17 & Proceso de gestión de investigadores & $\begin{array}{l}\text { A5: Capacitación permanente en metodología de investigación mediante } \\
\text { la web. } \\
\text { A6: Capacitación permanente en teorías, técnicas y métodos por la web. } \\
\text { A7: Capacitación permanente mediante análisis de investigaciones } \\
\text { realizadas por la web. } \\
\text { A8: Capacitación permanente en «mejores prácticas» por medio de la } \\
\text { web. } \\
\text { A12: Transmisión de conocimientos entre investigadores. } \\
\text { A13: Transferencia de conocimientos tácitos en el ámbito académico. }\end{array}$ \\
\hline P5 & & $\begin{array}{l}\text { A9: Consulta de recursos en web durante la investigación (revisar A5, } \\
\text { A6, A7 y A8) } \\
\text { A10: Consulta de recursos recomendados por comunidades virtuales }\end{array}$ \\
\hline
\end{tabular}

Elaboración propia. 


\section{Resultados y conclusiones}

- En el caso de los centros de investigación, es posible incorporar la gestión del capital intelectual y la gestión del conocimiento en la gestión de procesos, en un único modelo integrador.

- La gestión de procesos, basada en calidad, es insuficiente para gestionar los activos intangibles y garantizar así el sostenimiento en el largo plazo.

- Para el caso de la gestión de centros de investigación, incorporar la gestión de capital intelectual en la gestión de procesos tuvo el siguiente impacto:

- Los 9 procesos «formales» aumentaron a 17 procesos, que implica casi duplicar los procesos existentes. Hay que tener presente que algunos de los nuevos procesos ya se realizaban, pero de manera informal, y, en este caso, se requiere definirlos formalmente para su adecuada gestión.

o Se definieron 22 indicadores de capital intelectual, de los cuales 8 corresponden a capital humano; 7, a capital estructural y 7 , a capital relacional.

- Se transfirieron estos 22 indicadores de capital intelectual como indicadores de procesos. Por tanto, se requiere analizar y modificar los procesos involucrados, para que generen intangibles y provean de información para la medición de indicadores.

- Para el caso de la gestión de centros de investigación, la incorporación de la gestión del conocimiento en la gestión de procesos tuvo el siguiente impacto:

- Se definieron 15 actividades de generación de conocimiento, de las cuales 4 correspon- den a actividades de combinación; 1 , a actividad de exteriorización; 4, a actividades de socialización y 6 , a actividades de interiorización.

- En función de estos 4 tipos de actividades, se definieron 4 diferentes estrategias de generación de conocimiento: BA Sistematizador (Actividades de combinación); BA - Dialogante (Actividad de exteriorización); BA - Originario (Actividades de socialización) y BA - Operativo (Actividades de interiorización).

- Se incorporaron las 15 actividades de generación de conocimientos a los procesos. Estas nuevas actividades involucraron un total de 9 procesos; de los cuales solo uno de ellos -Proceso de investigación- debe mejorase porque corresponde a uno originalmente definido en la gestión de procesos basada en calidad; mientras que 8 procesos nuevos generados por incorporar la gestión del capital intelectual, deben diseñarse incluyendo las actividades propuestas.

- El presente ensayo contribuye con el conocimiento en el tema, ya que presenta un enfoque metodológico viable para incorporar la gestión del capital intelectual y la gestión del conocimiento en la gestión de procesos, como instrumentos de generación de valor en las organizaciones.

- A partir de este estudio, se pueden plantear investigaciones futuras en esta nueva perspectiva o línea de investigación. De esa manera, se puede demostrar que los beneficios incrementales de gestionar los procesos junto con la gestión del capital intelectual y la gestión del conocimiento, son superiores a los costos de implementación. 


\section{Referencias Bibliográficas}

BUENO, E. y OTROS

2001 «Gestión del conocimiento en universidades y organismos públicos de investigación». En: Revista Madri+d. Fecha de consulta: 12/07/ 2009.<http://www.madrimasd.org/ informacion/publicacion/doc/16_Gestion ConocimientoUniversidadesOPIS.pdf>

CHOO, C. W.

1999 La organización inteligente. El empleo de la información para dar significado, crear conocimiento y tomar decisiones. México: Oxford University Press.

DAVENPORT, T. H.

1999 Ecología de la Información. ¿Por qué la tecnología no es suficiente para lograr el éxito en la era de la información? México: Oxford University Press.

1996 Innovación de procesos. Madrid: Díaz de Santos.

DAVENPORT, T. H. y L. PRUSAK

2001 Conocimiento en acción. Cómo las organizaciones manejan lo que saben. Buenos Aires: Pearson Education.

KAPLAN, R. y D. NORTON

2000 El cuadro de mando integral. The Balanced Scorecard. $2^{a}$ edic. Barcelona: Gestión 2000.

LEV, B.

2003 Intangibles: medición, gestión e información. Barcelona: Ediciones Deusto.

MARIÑO N., H.

2003 Gerencia de procesos. Bogotá: Alfaomega.

NAVAS L., J. y M. ORTIZ DE URBINA

2002 «El capital intelectual en la empresa. Análi- sis de criterios y clasificación multidimensional». En: Economía Industrial, vol. 4, $N^{\circ}$ 346. Fecha de consulta: 15/02/2004. $<$ http://www.mcyt.es/asp/publicaciones/revista/numero346/163-171.pdf >.

NONAKA, I. y H. TAKEUCHI

1999 La organización creadora de conocimiento. Cómo las compañías japonesas crean la dinámica de la innovación. México: Oxford University Press.

VON KROGH, G.; K. ICHIJO e I. NONAKA

2001 Facilitar la creación de conocimiento. Cómo desentrañar el misterio del conocimiento tácito y liberar el poder de la innovación. México: Oxford University Press.

ZARATIEGUI, J. R.

1999 «La gestión por procesos: su papel e importancia en la empresa». Fecha de consulta: 20/09/2009. <http://www.bmg.cl/articulos// La\%20gestion\%20por\%20procesos\%20su\% 20papel\%20e\%20importancia.pdf>

\section{Páginas web}

International Organization Standardization (ISO) <http://www.iso.org/iso/home.htm>

Fundación Iberoamericana del Conocimiento (FIC) $<$ http://www.gestiondelconocimiento.com>

Fundación Iberoamericana para la Gestión de Calidad $<$ http://www.fundibeq.org $>$.

Madri+d: red de trabajo y cooperación de universidades y centros de investigación vinculadas a la I+D+l. $<$ http://www.madrimasd.org> 